\title{
An assessment of regional sea ice predictability in the Arctic ocean
}

\author{
3 Rubén Cruz-García - Virginie Guemas . \\ 4 Matthieu Chevallier . François Massonnet
}

5

6 Received: 20 March 2018 / Accepted: 18 December 2018 / Published online: 05 January 2019

7 Abstract Arctic sea ice plays a central role in the Earth's climate. Changes in 8 the sea ice on seasonal-to-interannual timescales impact ecosystems, populations 9 and a growing number of stakeholders. A prerequisite for achieving better sea ice predictions is a better understanding of the underlying mechanisms of sea ice predictability. Previous studies have shown that sea ice predictability depends on the predictand (area, extent, volume), region, and the initial and target dates. Here we investigate seasonal-to-interannual sea ice predictability in so-called "perfectmodel" 3-year-long experiments run with six global climate models initialized in early July. Consistent with previous studies, robust mechanisms for reemergence are highlighted, i.e. increases in the autocorrelation of sea ice properties after an initial loss. Similar winter sea ice extent reemergence is found for HadGEM1.2, GFDL-CM3 and E6F, while a long sea ice volume persistence is confirmed for all models. The comparable predictability characteristics shown by some of the peripheral regions of the Atlantic side illustrate that robust similarities can be found even if models have distinct sea ice states. The analysis of the regional sea ice predictability in EC-Earth2.3 demonstrates that Arctic basins can be classified according to three distinct regimes. The central Arctic drives most of the panArctic sea ice volume persistence. In peripheral seas, we find predictability for the sea ice area in winter but low predictability throughout the rest of the year, due to the particularly unpredictable sea ice edge location. The Labrador Sea stands out among the considered regions, with sea ice predictability extending up to 1.5 years if the oceanic conditions upstream are known.

Rubén Cruz-García, Virginie Guemas

Barcelona Supercomputing Center (Centro Nacional de Supercomputación), Nexus II - Planta 1, C/ Jordi Girona 29, Barcelona 08034

E-mail: ruben.cruzgarcia@bsc.es

Matthieu Chevallier

Centre National de Recherches Météorologiques/Groupe d'Etude de l'Atmosphère Météorologique, Météo-France, CNRS, Toulouse, France

François Massonnet

Georges Lemaître Centre for Earth and Climate Research, Earth and Life Institute, Université catholique de Louvain, Louvain-la-Neuve, Belgium 
Keywords Sea ice · Regional · Arctic · Predictability

\section{Introduction}

Sea ice is an early indicator of climate change and an amplifier of climatic perturbations (e.g., Serreze and Barry, 2011; Vihma, 2014). At seasonal-to-interannual timescales, sea ice may influence the climate of mid and high latitude regions (e.g., Deser et al., 2010; Francis and Vavrus, 2012; Liu et al., 2012; Yang and Christensen, 2012), as well as the Arctic Ocean biology and atmospheric chemistry (Bhatt et al., 2014). The rapid decline in sea ice in the past few decades, associated with polar temperature amplification, resulted in the scientific community paying more attention to predictions at seasonal-to-interannual timescales. For example, reliable predictions of sea ice conditions in maritime shipping routes in the Arctic, e.g. the Northwest Passage or the Northern Sea Route, would help the planning of shorter and cheaper trade routes between the Atlantic and Pacific Oceans (Hassol, 2004), and could benefit the growing ecotourism industry in the Arctic.

Sea ice predictability has been assessed in various frameworks, including idealized perfect-model experiments. In such experiments, model simulations are used as a surrogate for the real climate, to estimate the extent to which the model can predict itself. Ensemble predictions are initialized from a control run by introducing small perturbations. Potential predictability is a measure of the amplification of those perturbations, i.e. the fraction of the signal which is inherently not predictable. Such experiments using state-of-the-art models also provide an indication of the maximum level of skill that could be achieved in real predictions if all the observations required to initialize the predictions were available, and if all processes were perfectly represented by the models.

Tietsche et al. (2014) performed the first multi-model evaluation of Arctic sea ice potential predictability on seasonal-to-interannual timescales, in a coordinated perfect-model framework defined in the Arctic Predictability and Prediction on Seasonal-to-Interannual Timescales (APPOSITE) project (Day et al., 2016; Tietsche et al., 2014). Each of the seven participating groups ran a set of 3-year long ensemble prediction experiments, initialized from a present-day control experiment near July 1 . They showed that even if two models have significant predictability -based on a comparison of the ensemble spread and the natural control variabilityfor the sea ice volume (SIV; up to 3 years) for similar forecast times, differences in the representation of local advective processes could lead to large differences in the regional sea ice thickness (SIT) predictability. They suggested that advective sea ice processes may induce an amplification of forecast errors close to the coasts in the Arctic Ocean in winter.

A similar perfect-model approach was also followed by Day et al. (2014). In a set of 5 models, they found similar SIE predictability reemergence mechanisms (which is the increase of predictability after an initial drop), consistent with the summerto-summer and melt-to-freeze mechanisms described by Blanchard-Wrigglesworth et al. (2011). They also found that when starting the predictions in May, the forecasts lost skill more rapidly in the first 4 months than when initialized in January or July. Another robust result was that the SIE in the seasonal ice zone of the North Atlantic region is significantly predictable 1.5-2.5 years ahead, while in the central Arctic it is less than 1 year (Day et al. (2014) defined predictability 
as the timescale for which the ensemble root-mean-square-error (RMSE) is below the climatological RMSE, using an $f$ test for significance).

Several studies have focused on the sea ice predictability of different Arctic basins (Bushuk et al., 2018; Cheng et al., 2016; Day et al., 2014; Koenigk and Mikolajewicz, 2009). However, the mechanisms behind the regional sea ice predictability are not yet well established. To understand the Arctic sea ice cover predictability, a regional approach is needed to disentangle the different drivers of variability, which depend on the location (e.g. Bitz et al., 2005; Francis and Hunter, 2007; Schlichtholz, 2011; Tietsche et al., 2016). For instance, Bitz et al. (2005) showed that the ocean heat flux convergence is a large heat source in the marginal ice zone of the Barents Sea, but a relatively small source in the Labrador Sea. Likewise, Francis and Hunter (2007) suggested that the zonal wind anomalies influence the Bering Sea winter ice edge location, while the Barents Sea ice edge seems to be controlled primarily by anomalies in SST during the late winter and by anomalous meridional winds.

Regional metrics tend to have lower predictability than integrated ones (e.g. Day et al., 2014; Goessling et al., 2016). Blanchard-Wrigglesworth et al. (2016) highlighted this contrast between pan-Arctic and regional predictability with a multimodel approach, where all models initialized with identical SIT could uniformly predict September SIE anomalies, but did not show agreement regarding the spatial SIC anomalies patterns.

In the present paper, we perform a regional sea ice assessment for six of the APPOSITE project models, with a focus on the European Consortium Earth System Model version 2.3 (EC-Earth2.3 hereafter; Hazeleger et al. (2012)), since mechanisms of predictability can be investigated in greater depth for this model by, for example, projecting water mass backward trajectories. In this context, we consider sub-regions in the central Arctic and in the margins connecting the Pacific and Atlantic Oceans. We also relate the highlighted mechanisms to those previously attributed to pan-Arctic sea ice predictability (including persistence and reemergence).

This paper is structured as follows: In section 2, we describe our methodology, including the experimental protocol and the metrics used to quantify sea ice potential predictability. Section 3 presents the assessment of Arctic sea ice potential predictability at the pan-Arctic and regional scale for each of the APPOSITE models (except CanCM4). Section 4 discusses the mechanisms behind the regional sea ice predictability of EC-Earth2.3 and section 5 provides the main conclusions.

\section{Methodology}

\subsection{Multimodel analysis and experimental setup}

We estimated an upper limit for the predictability of Arctic SIE and SIV using six of the seven coupled global climate models from the APPOSITE project (Day et al., 2016): EC-Earth2.3 (Hazeleger et al., 2012), MIROC5.2 (Watanabe et al., 2010), HadGEM1.2 (Johns et al., 2006; Shaffrey et al., 2009), GFDL-CM3 (Donner et al., 2011; Griffies et al., 2011), MPI-ESM (Jungclaus et al., 2013; Notz et al., 2013) and E6F (Sidorenko et al., 2015). The CanCM4 model was discarded because of its short control simulation length. These models have already been evaluated 
in the multimodel assessment of Tietsche et al. (2014), and a few characteristics of the APPOSITE simulations are shown in Day et al. (2014).

Each APPOSITE working group provided a control simulation (hereafter referred to as ControlRun) and a set of predictions that started from the control (hereafter referred to as IdealPred). In this paper we use the predictions that were started from July. Note that in this perfect-model protocol, the ControlRun is also the reference dataset for evaluating the performance of the idealized climate predictions.

Each prediction member has a slightly different perturbation of the initial state obtained by introducing a $10^{-4} \mathrm{~K}$ magnitude white noise in the sea surface temperature (SST). The start dates were selected to sample a range of high, low and medium sea ice states, with consideration of the Atlantic heat transport into the Arctic (AHT hereafter; calculated as the heat transport through the section formed by the sum of the Fram Strait plus the Barents Sea Opening, represented by the black thick lines in Fig. 1). Start dates are spaced sufficiently apart in time to make them as independent as possible. More details can be found in Day et al. (2016).

\subsection{Diagnostics}

Our analysis is performed using monthly data for the pan-Arctic SIE and SIV. Regional assessment is done for the basins shown in Fig. 1.

In this study, potential predictability is estimated both in a prognostic and diagnostic way (Boer, 2004). Simple estimates of the diagnostic potential predictability are calculated using lagged anomaly correlations in the ControlRun as in Blanchard-Wrigglesworth et al. (2011). The prognostic potential predictability uses the methodology described in Pohlmann et al. (2004), and is estimated using both the control simulation and the idealized experiments.

In both cases, anomalies are calculated as follows. For each date, a 40-yearwindow taken from the ControlRun and centered around that date is used to filter out low-frequency variability and the remaining long-term drift. The mean annual cycle over that period is used as a reference to compute the anomalies in the IdealPred experiments. To be consistent, we also apply this protocol to determine the anomalies across the ControlRun, using 40-year running windows, as:

$$
Z_{g}^{\prime}=Z_{g}-\bar{Z}_{g}^{[-20 y ;+20 y]}
$$

where $g$ is the selected month of the raw data $Z, \overline{Z_{g}}$ is the average of the 40 same calendar months around the selected date and $Z_{g}^{\prime}$ is the anomaly of month $g$ compared to the average annual cycle of the 40-year window.

Following this, the natural variability is calculated as:

$$
\sigma_{c}(g)=\sqrt{\frac{\sum_{Y_{0}}^{Y_{l}}\left(Z_{g}^{\prime}(y)\right)^{2}}{Y_{l}-Y_{0}}}
$$

where $Z_{g}^{\prime}(y)$ is the anomaly for month $g$ and year $y, Y_{0}$ and $Y_{l}$ are the first and last year, respectively, considered in the summation. Note that the use of the 40 -year running windows excludes 20 years at the beginning and end of the whole simulation. 


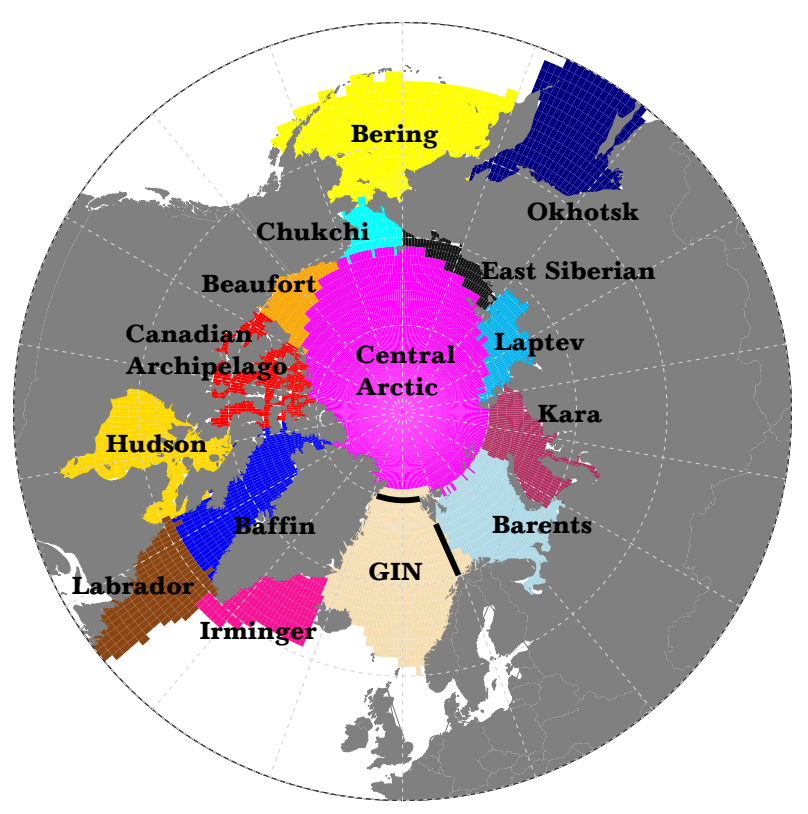

Figure 1: Map of the Arctic seas as defined in this study. The black lines indicate the sections used for the calculation of the Atlantic heat transport into the Arctic (Fram Strait plus Barents Sea Opening). The GIN region is formed by the Greenland, Icelandic and Norwegian seas.

The level of potential predictability is estimated using the intra-ensemble spread (i.e. the spread around the ensemble mean), as a function of the forecast time:

$$
\sigma_{e}(t)=\sqrt{\frac{\sum_{m=1}^{M} \sum_{s=1}^{S}\left(Z_{m, s}(t)-\overline{Z_{s}(t)}\right)^{2}}{M \cdot S}}
$$

where $M$ is the total number of members, $S$ is the total number of start dates, $Z_{m, s}(t)$ is the predicted value of our variable at forecast time $t$ for ensemble member $m$ initialized at start date $s$ and $\overline{Z_{s}}$ is the predicted value for the same start date and forecast time averaged across the whole ensemble.

We consider the prognostic potential predictability (PPP hereafter; Germe et al., 2014; Pohlmann et al., 2004). The PPP compares the ensemble spread with an estimate of the amplitude of the natural variability of the system based on the standard deviation of the control simulation (e.g. Koenigk and Mikolajewicz, 2009). It is an estimate of the initial predictability and is defined as:

$$
P P P(t)=1-\frac{\sigma_{e}^{2}(t)}{\sigma_{c}^{2}(g)}
$$

where $\sigma_{e}^{2}$ is the variance across the ensemble members (IdealPred) at forecast time $t$ and $\sigma_{c}^{2}$ is the variance of the control integration ControlRun for the relevant month $g$. A PPP value of 1 would mean that the system is perfectly predictable (i.e. the ensemble members of the predictions did not diverge over time), whereas 
a PPP value of zero or less indicates that there is no predictability because the ensemble spread is equal to that expected from natural variability (Holland et al., 2011). Unlike the RMSE, this metric allows us to compare the dispersion of the ensemble with respect to the reference variability in a single number, giving us an idea of the proportion at every timescale, even when both of them are very small and similar.

\section{Multimodel potential predictability of pan-Arctic and regional sea ice}

Pan-Arctic sea ice. The pan-Arctic SIE PPP decreases at a similar rate for the first six months after initialization for all models (Fig. 2a). From the first December there is a consistent predictability reemergence for HadGEM1.2, GFDL-CM3 and E6F every winter, but a lack of significant predictability during the summer. The dominance of the positive ice-albedo feedback could explain the faster intraensemble spread growth (the decrease of PPP; see formula 4) during the melting season, whereas the increase in PPP during the freezing season could originate from the negative ice thickness-growth rate feedback, acting as amplifiers and dampeners of the initial perturbations of the sea ice conditions, respectively (Tietsche et al., 2014). This seasonality in the signal is not present in MPI-ESM, for which SIE is not significantly predictable beyond December Year 1. For EC-Earth2.3 the PPP decrease is sharper after the first October, when the sea ice gradually spreads across the interior of the Arctic basin and peripheral seas outside the Arctic Ocean. The significant reemergence before the second freezing season seems to be characteristic of EC-Earth2.3, although MIROC5.2 also presents a significant PPP the second and third July. This might be related to an "early" summer-to-summer predictability mode for July, as can be seen in their correspondent lagged correlation matrices (Fig. 2 of the supplementary material). This mechanism does not appear for the rest of models in July, but it does in September (Fig. 2 of the supplementary material). The summer-to-summer memory reemergence has its origin in the summer SIT memory (from the central Arctic) (Blanchard-Wrigglesworth et al., 2011). Over three continuous years, the central Arctic September SIV and the SIE are correlated in September (Fig. 3, red line) for all models.

The long-lasting IdealPred SIV potential predictability (Fig. 2b) is related to the persistence of the SIV, as shown by the lagged correlations calculated from the ControlRun (Fig. 3 of the supplementary material). HadGEM1.2 does not pass the test of significance for the PPP for any leadtime due to the strict criteria we applied: we removed the points where more than half of the corresponding values are lower than $1 \%$ of the average anomaly or zero. The persistence of the SIV at the pan-Arctic scale arises almost entirely from the central Arctic SIV persistence (Blanchard-Wrigglesworth et al., 2011), as suggested when the lagged correlation of the central and pan-Arctic SIV are compared (Fig. 3, blue and black lines correspondingly).

In the following, we split the Arctic Ocean and surrounding basins considered in Fig. 1 into two groups, based on their seasonality: group one is the peripheral basins including the summer ice-free regions (Barents Sea, Kara Sea, GIN seas, Irminger Sea, Baffin Bay, Labrador Sea, Hudson Bay, Bering Sea, Sea of Okhotsk and Chukchi Sea), and group two is the internal Arctic seas, or the seas that are 


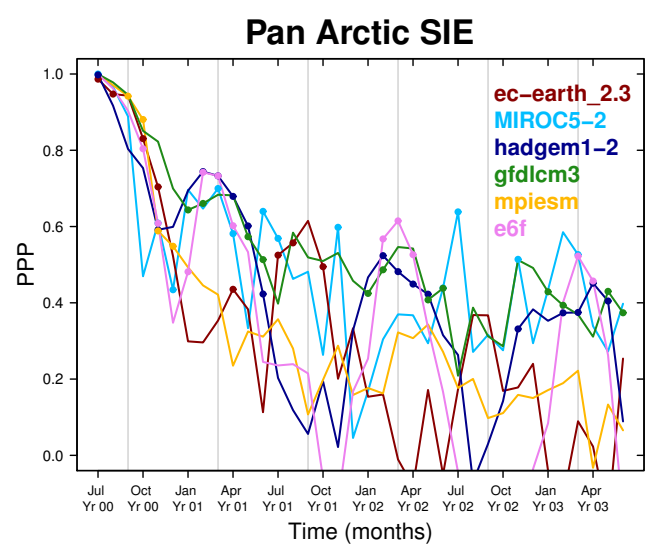

(a)

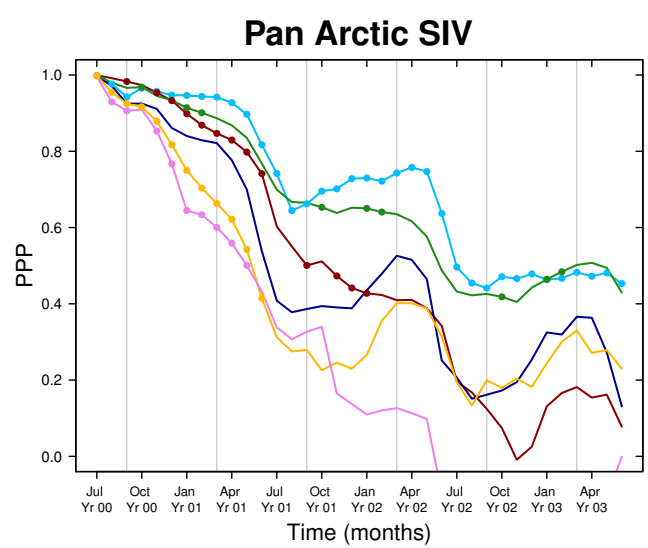

(b)

Figure 2: Potential predictability of the pan-Arctic (a) SIE and (b) SIV measured with the PPP of IdealPred using the natural variability of ControlRun as a reference. Dots indicate significant values at the $95 \%$ level, estimated by an F-test. Significant data points where more than half of the corresponding values in the control are zero were removed. The data points where more than half of the control are lower than the $1 \%$ of the average anomaly, for each predictand, month and region were also removed. September and March are marked by thin gray vertical lines.

entirely ice covered during winter (the "central basins"; central Arctic, Canadian Archipelago, Beaufort Sea, East Siberian Sea, Laptev Sea).

Peripheral basins. A regional analysis revealed large variations in the SIE and SIV potential predictability (Fig. 4-5). Nevertheless, some common features can be seen. For instance, in all the peripheral basins (except Hudson Bay and Chukchi; Fig. $4 \mathrm{a}-\mathrm{j}$ ) the PPP shows the same temporal pattern for the SIE as for the SIV (for each model individually), which reflects the correlation between ice concentration and ice thickness in those regions with a thin ice cover. In the Barents, Kara and GIN seas, and in Baffin Bay, sea ice is present in July at the start of IdealPred for all models. The PPP initially decreases, before peaks of reemergence occur at different lead times depending on the model and basin. The Barents, Kara and Chukchi seas SIV PPP exhibit a significant predictability reemergence in summer for most models. This might be directly linked to the retreat/advance mechanism of predictability (Blanchard-Wrigglesworth et al., 2011; Stammerjohn et al., 2012). We can cluster the GIN and Baffin Bay within the same group: there is an initial predictability drop followed by a memory reemergence in winter, which seems robust for all models. On the Pacific side (Bering and Okhotsk seas) sea ice is not present at the start of the predictions (except for HadGEM1.2). For these seas the PPP is noisier and less significant than in the Atlantic sector. We could not group the rest of peripheral seas because of the differences shown in the temporal variability of PPP between the models. This is mainly due to the differences in 


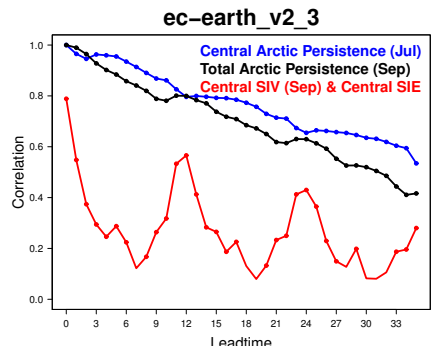

(a)

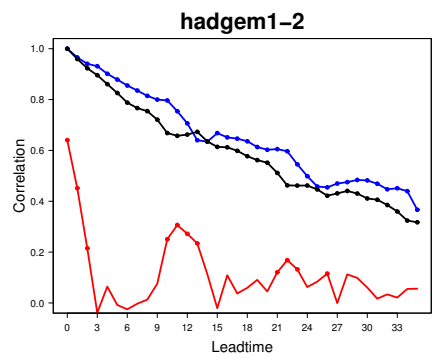

(d)

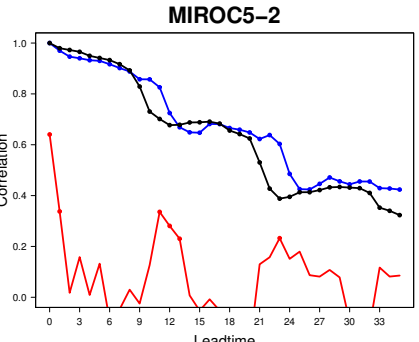

(b)

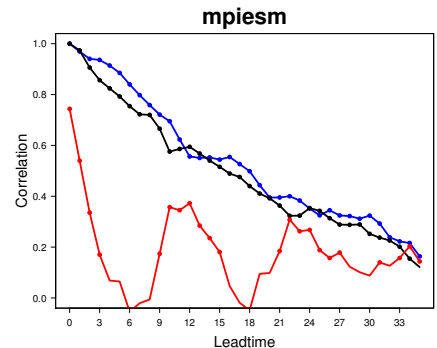

(e)

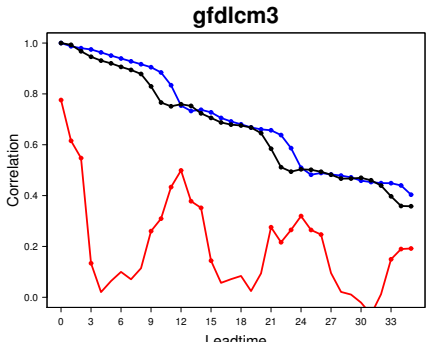

(c)

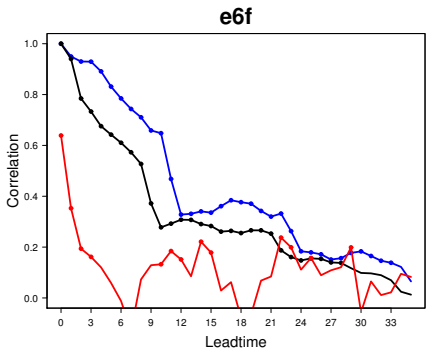

(f)

Figure 3: In blue, the July central Arctic SIV autocorrelation. In black, the September ControlRun lagged autocorrelation for the pan-Arctic SIV. In red, the lagged correlation between the September central Arctic SIV and the central Arctic SIE. Dots indicate significant values at the $95 \%$ level as estimated from a one-sided student-T distribution.

the mean sea ice state between the different models. To know more about these differences, please see Day et al. (2016). In the following section we consider these regions in greater detail in EC-Earth2.3.

Central basins. The SIE PPP in the interior basins other than the central Arctic (Fig. 4l-o) is null during the winter due to the extremely low sea ice variability. The central Arctic SIE PPP reflects how the different model sea ice conditions (and the cycle of variance) impact predictability. In most central regions, the PPP of the SIV continuously decays over time while remaining statistically significant up to 614 months (even until the third year for MIROC5.2 in the Canadian Archipelago). This suggests that the regional SIV is potentially predictable up to one year in advance for the seas with perennial sea ice. The significant reemergence of SIV PPP in the Beaufort Sea stands out for all models except for EC-Earth2.3 and HadGEM1.2. The central Arctic region exhibits the same PPP characteristics as the pan-Arctic region for the SIV, which is an indicator of the origin and sources of predictability of the pan-Arctic sea ice. 


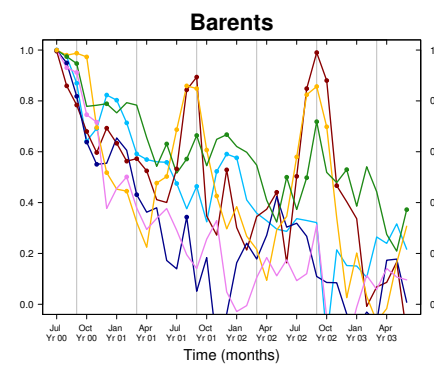

(a)

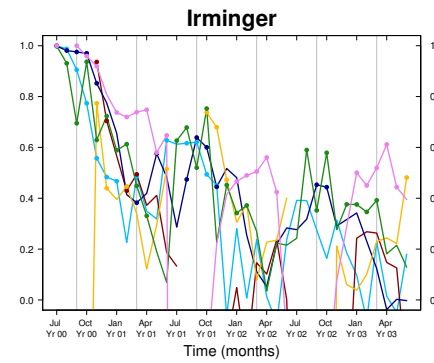

(d)

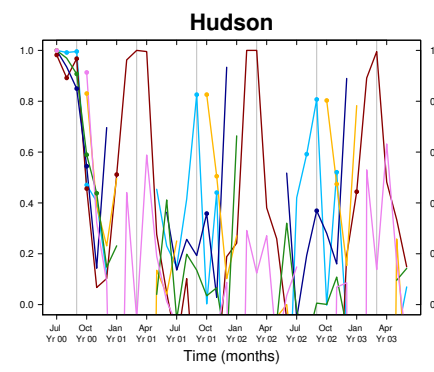

(g)

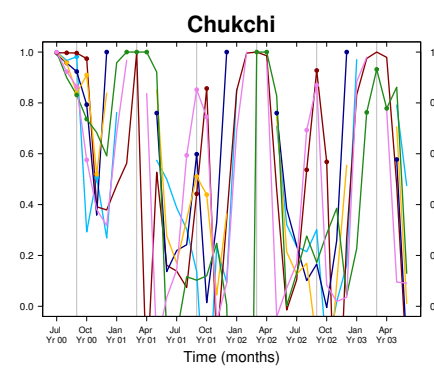

(j)

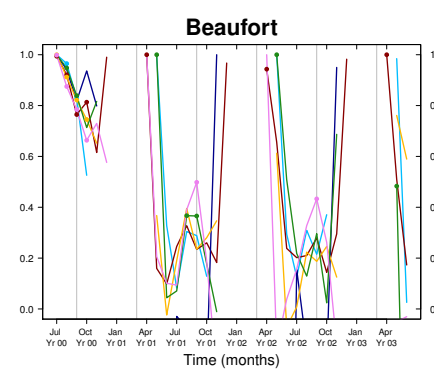

$(\mathrm{m})$

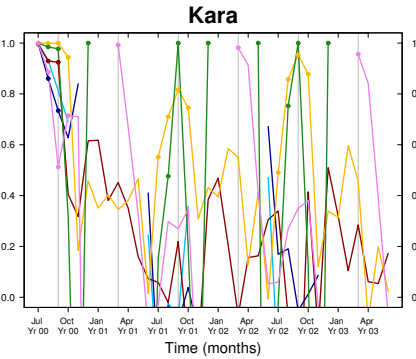

(b)

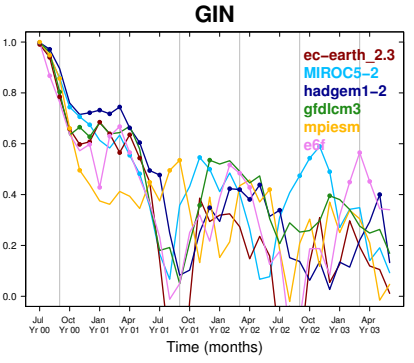

(c)

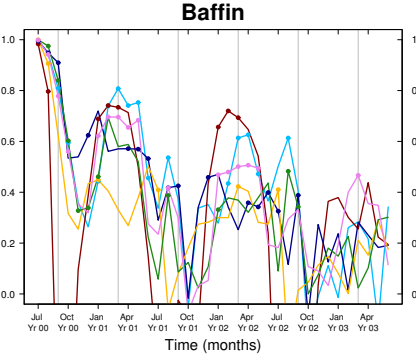

(e)

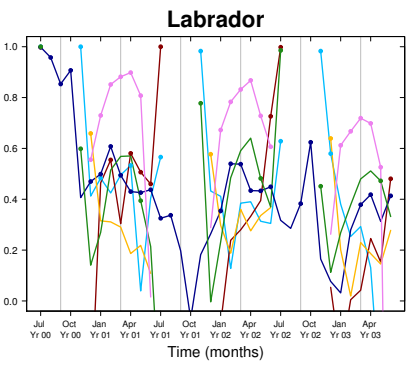

(f)

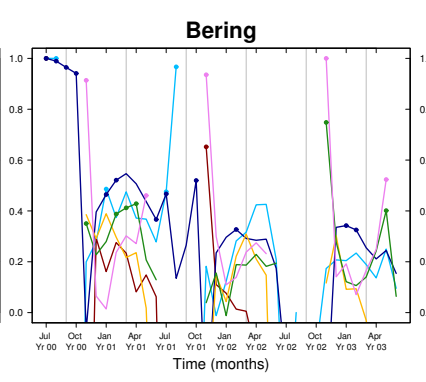

(h)

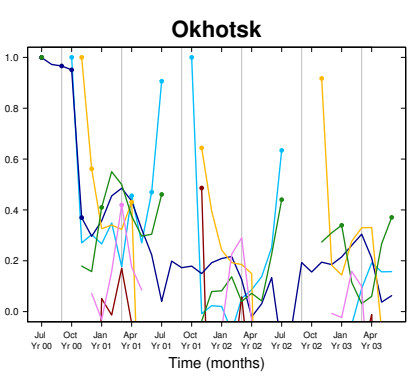

(i)

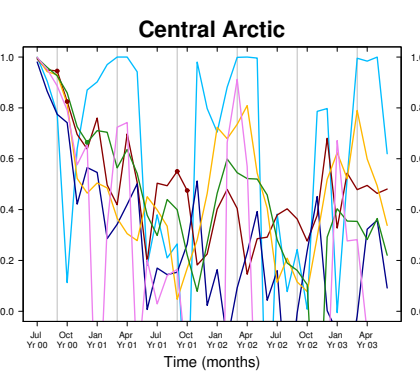

(k)

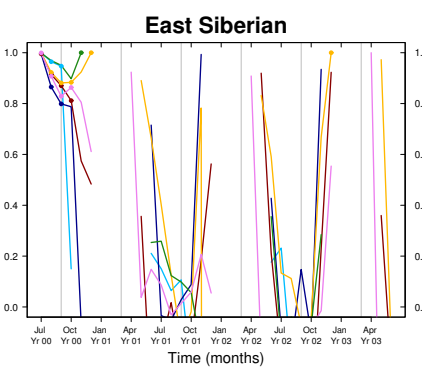

(n)

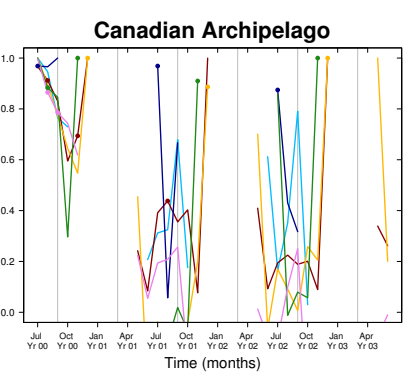

(l)

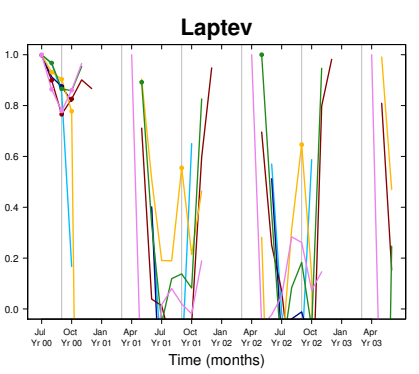

(o)

Figure 4: Regional SIE potential predictability measured as the PPP of IdealPred using the natural variability of ControlRun as a reference. Dots indicate significant values at the $95 \%$ level, estimated by an F-test. September and March are marked by thin gray vertical lines. 


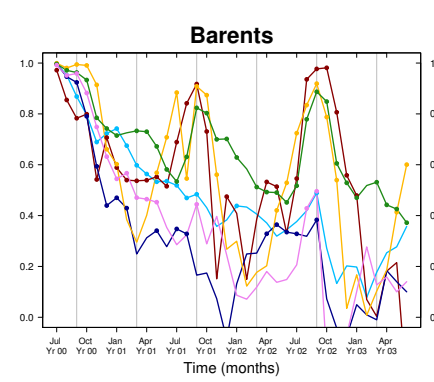

(a)

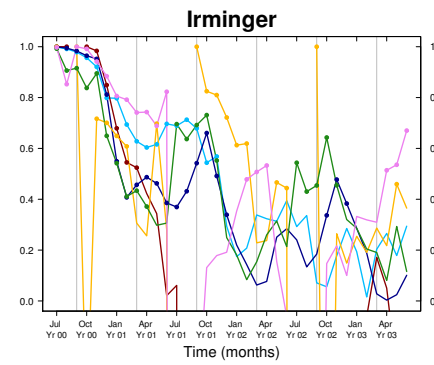

(d)

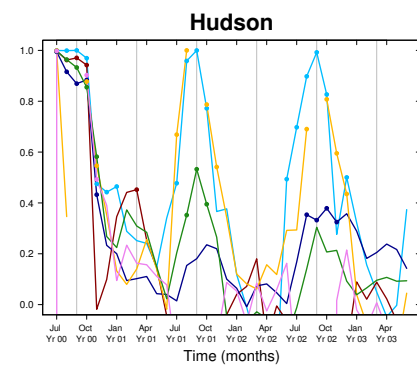

(g)

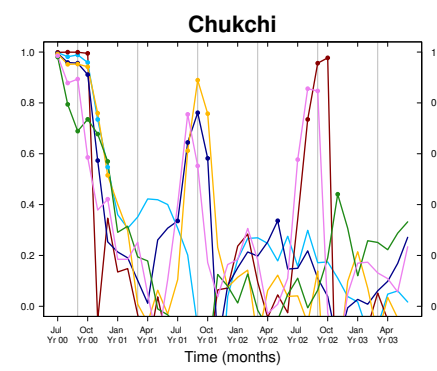

(j)

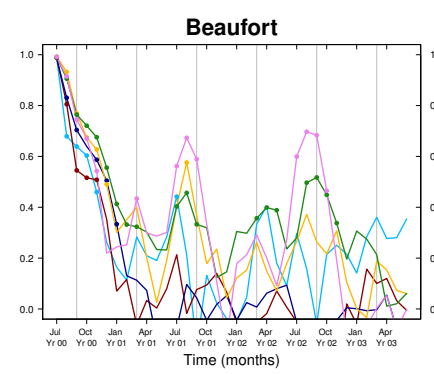

$(\mathrm{m})$

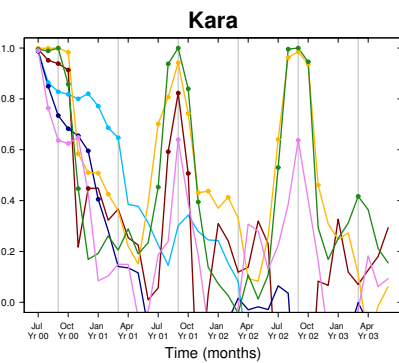

(b)

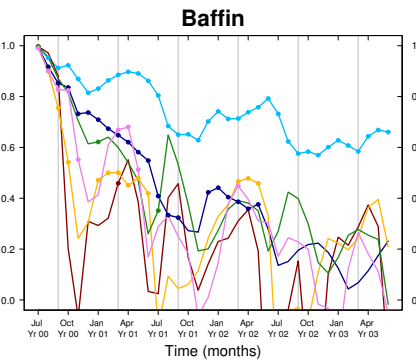

(e)

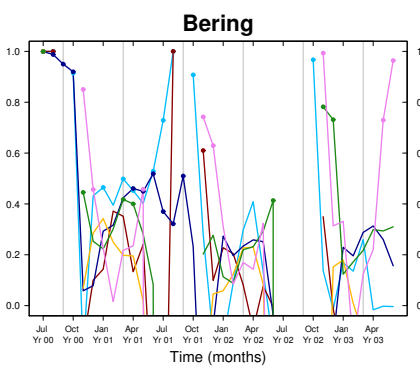

(h)

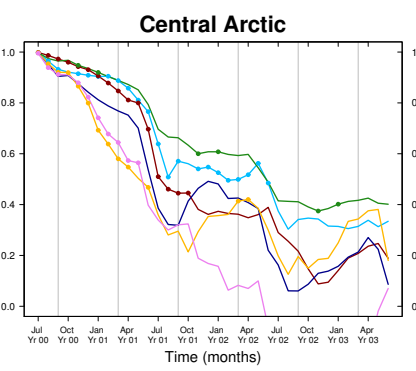

(k)

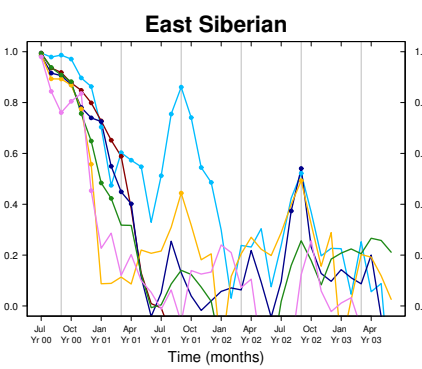

(n)

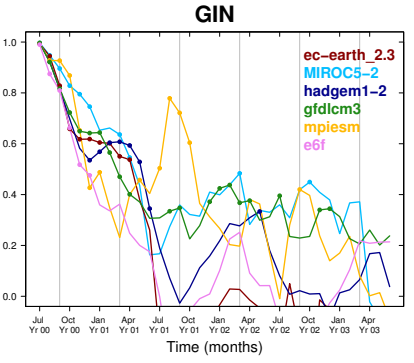

(c)

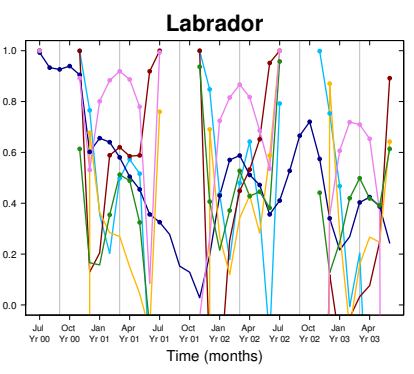

(f)

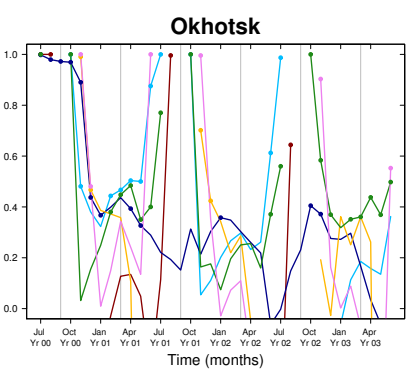

(i)

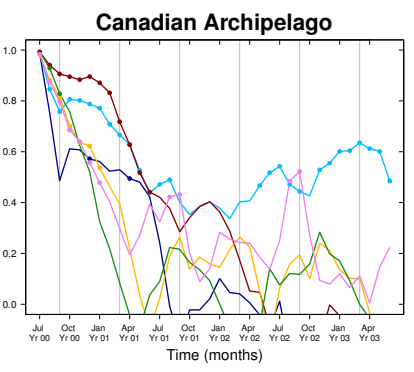

(1)

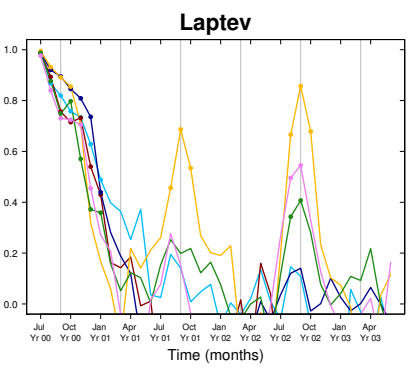

(o)

Figure 5: Regional SIV potential predictability measured as the PPP of IdealPred using the natural variability of ControlRun as a reference. Dots indicate significant values at the $95 \%$ level, estimated by an F-test. September and March are marked by thin gray vertical lines. 


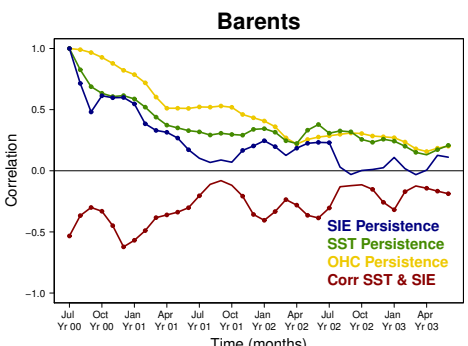

(a)

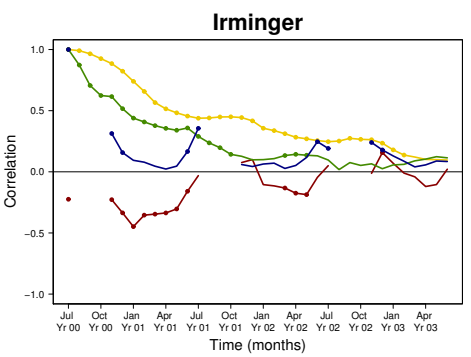

(d)

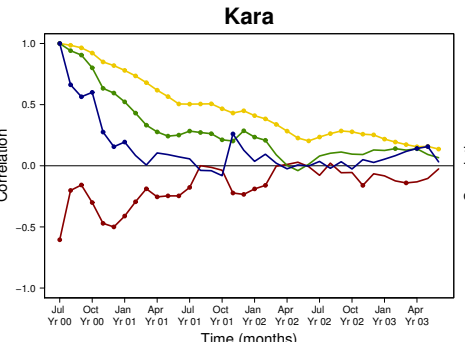

(b)

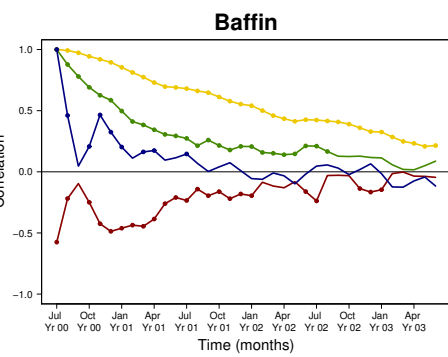

(e)

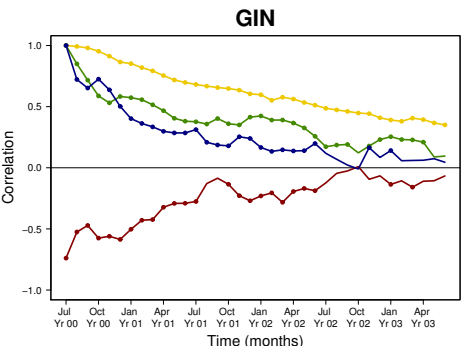

(c)

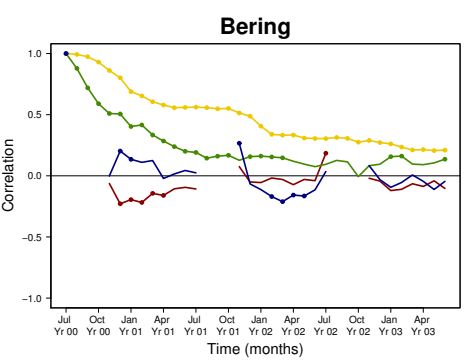

(f)

Figure 6: The persistence of the SIE (blue), the SST (green) and the OHC (0-300 m depth, yellow) in the (a) Barents, (b) Kara, (c) GIN, (d) Irminger, (e) Baffin Bay and (f) Bering seas for EC-Earth2.3. In red, the lagged correlation between the July SST and the SIE for the same seas. Correlations were calculated using the ControlRun during the three subsequent years. Dots represent significant values at the $95 \%$ level as estimated from a one-sided student-T distribution.

In spite of the initial decay, the PPP still has significant values in the Barents, Kara, and GIN seas and in Baffin Bay for the SIE and SIV (Fig. 4/5a-c \& e). The memory of the sea ice cover in these regions can be related to the long-term persistence of the July SST anomalies at the same location (Fig. 6a-c \& e, green lines), which also varies with the ocean heat content (integrated over the first 300 meters depth; OHC hereafter). Thus, the memory of sea ice cover in the peripheral seas has a partially oceanic origin (Fig. $6 \mathrm{a}-\mathrm{c} \&$ e, yellow lines). 
The SIE lagged correlations (Fig. $6 \mathrm{a}-\mathrm{c} \& \mathrm{e}$, blue lines) show a melt-to-freeze reemergence and significant predictability over the first year. The PPP highly depends on the start dates and the mean climate state, as we have already shown in section 2.2, so in this case the ControlRun provides a more robust idea of the regional predictability, but the mechanisms are comparable. The SST during the previous spring provides predictability of the December SIE (Fig. $7 \mathrm{a}-\mathrm{c} \&$ e). The maps of the correlation between the grid point SST in December and the averaged December to February SIE in the Barents and Kara seas (Fig. 8a-b) agree with the time series in Fig. 7 .

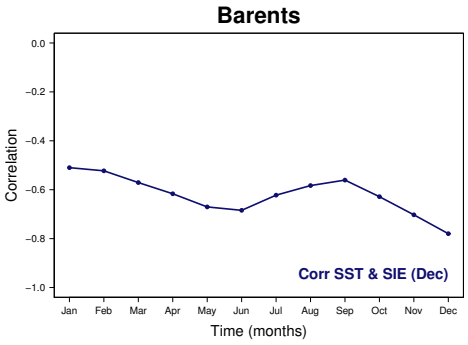

(a)

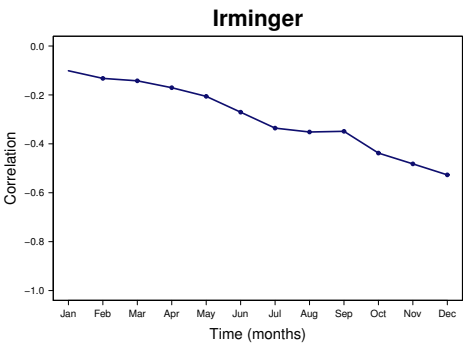

(d)

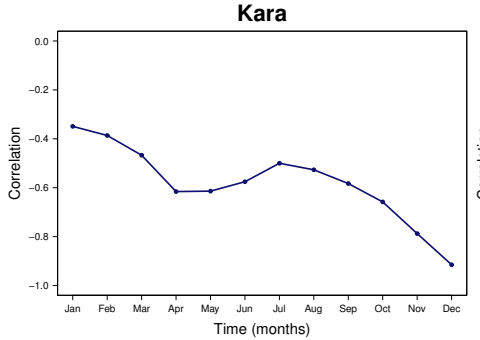

(b)

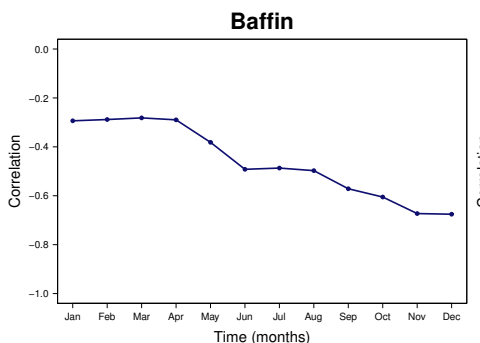

(e)

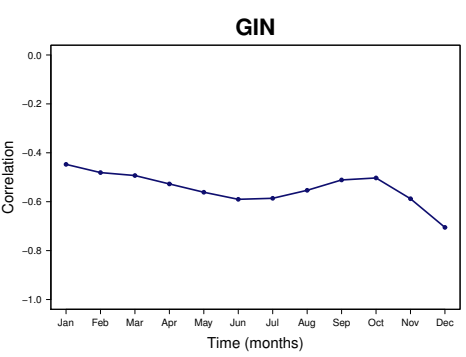

(c)

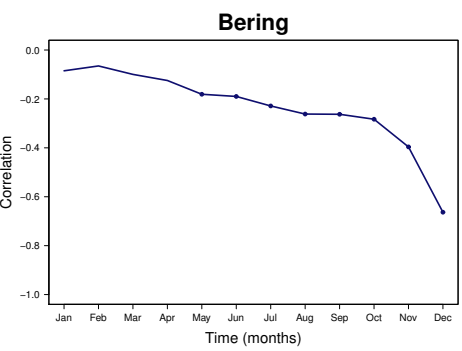

(f)

Figure 7: Correlation between December SIE and SST in the previous year in the (a) Barents, (b) Kara, (c) GIN, (d) Irminger, (e) Baffin Bay and (f) Bering seas for EC-Earth2.3. Correlations were calculated using the ControlRun. Dots represent the significant values at the $95 \%$ level as estimated from a one-sided student-T distribution.

\subsection{Ocean reemergence in the Labrador Sea}

We investigated the peak of PPP in January-April in the Labrador Sea, which is not present in other peripheral seas and does not seem to project onto the changes in the pan-Arctic PPP in Fig. 2a. This peak cannot be attributed to a reemergence mechanism due to sea ice, since sea ice is not present at the start of the prediction in this area for EC-Earth2.3. 


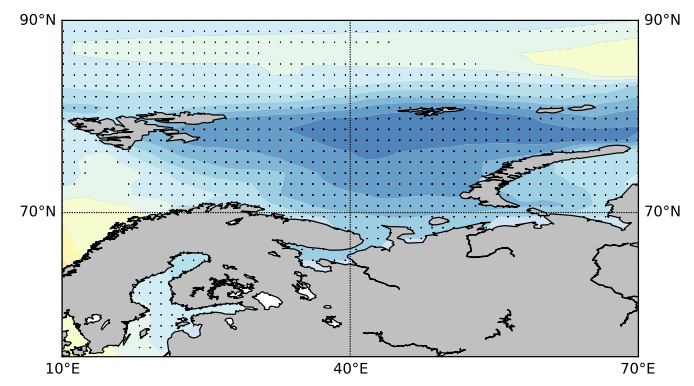

(a)

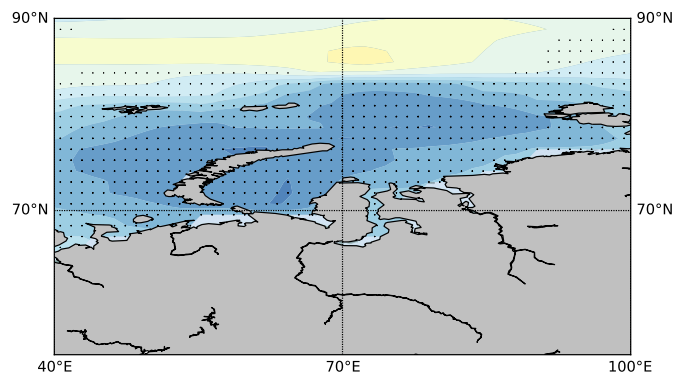

(b)

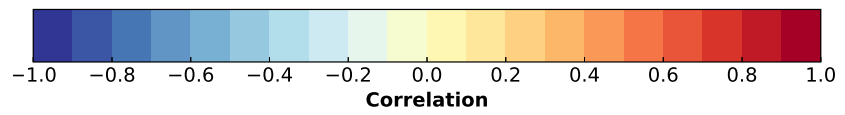

Figure 8: Maps of correlation between the gridpoint December SST and (a) Barents and (b) Kara SIE for December, January and February (mean correlation) for EC-Earth2.3. Black dots indicate significant correlations at the $95 \%$ level as calculated from a one-sided student-T distribution.

We tested the hypothesis that this memory reemergence had a remote origin. We calculated several backward water mass trajectories using the off-line mass preserving Lagrangian Ariane scheme (Blanke et al., 1999; Blanke and Raynaud, 1997). Here, 25 tracers were seeded uniformly, all at a 5-m depth (depth of the uppermost ocean level) in the Labrador Sea in February, and their origin was traced using the 40-year average monthly velocity fields from the ControlRun. Our target was to find the locations of those water parcels in the first July month, 8 (i.e. target February Year 1), 20 (i.e. target February Year 2) or 32 (i.e. target February Year 3) months before. The trajectories are shown in Fig. 9a-c.

The trajectories reveal that the water parcels present in the Labrador Sea at the time of the first two SIE PPP peaks originate from the subpolar gyre area. During the first year, the local correlations, ie. Labrador SST and OHC correlated with Labrador SIE (Fig. 9d, red and green lines), show that the reemergence is related to the subpolar gyre persistence (Fig. 10a). The second year, the correlations between the Irminger Sea SST and OHC at the time of the initialization and the Labrador Sea SIE are higher than the local correlations, and they match exactly the time when the PPP reemergence in the Labrador Sea occurs (Fig. 9d, blue and black lines). For longer timescales, these parcels have their origins in the North Atlantic. Thus, the first winter peak of the PPP of the SIE in the Labrador Sea seems related to the subpolar gyre persistence, while the second is caused by anomalies in the SST advected from a remote location in the Irminger Sea.

As a result of advective ocean processes, sea ice predictability in the Labrador Sea may be related to predictability in the subpolar gyre circulation. Indeed, previous studies have highlighted the high SST predictability in the subpolar gyre area (Boer, 2004; Collins, 2002), including studies using the same climate model (Wouters et al., 2013). Koenigk and Mikolajewicz (2009) confirmed that advection 


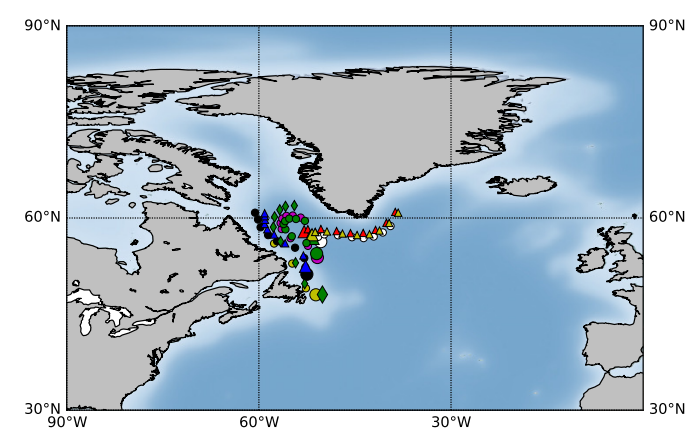

(a)

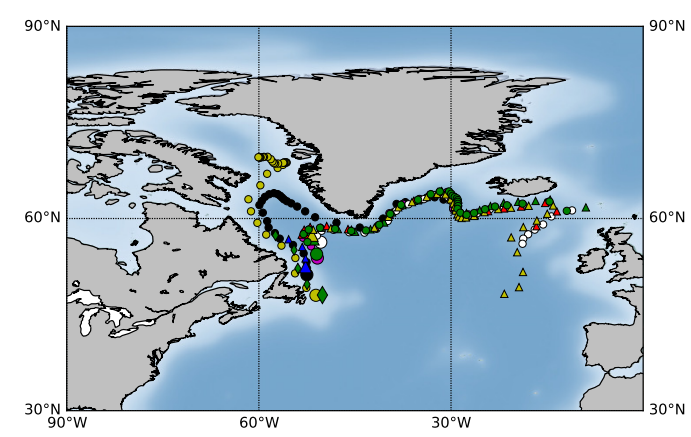

(c)

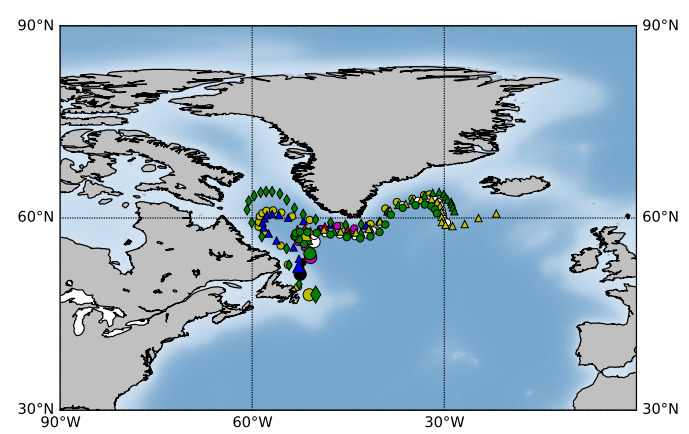

(b)

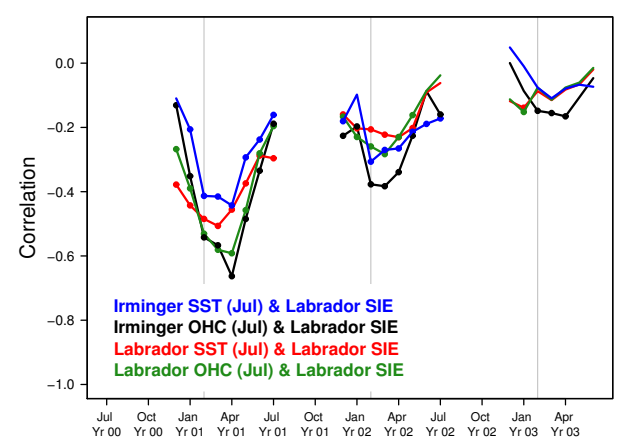

(d)

Figure 9: Map of the backward trajectories followed by water masses travelling from different locations in the Labrador Sea from (a) the first, (b) the second and (c) the third February until the first July for EC-Earth2.3. Each lead time is marked with a dot, while the initial positions (corresponding February) are marked with bigger dots. (d) Correlation between the Irminger Sea SST, the Irminger Sea OHC, the Labrador Sea SST and the Labrador Sea OHC the first July and the Labrador Sea SIE the three following years for the ControlRun. Dots represent the significant values at the $95 \%$ level estimated from a one-sided student-T distribution. The vertical grey lines represent the months of February. The SST and OHC were integrated for the corresponding area in Fig. 1.

of SST anomalies may lead to an increase in the predictability of the Barents sea ice in winter. This result, consistent with previous studies, suggests that the initialization of the ocean is important when running real initialized sea ice forecasts.

\subsection{Sea ice thickness persistence in the internal Arctic basins}

We mentioned above that the summer peaks of the PPP for the pan-Arctic SIE could be attributed to the persistence of the SIT in the central Arctic, as suggested 


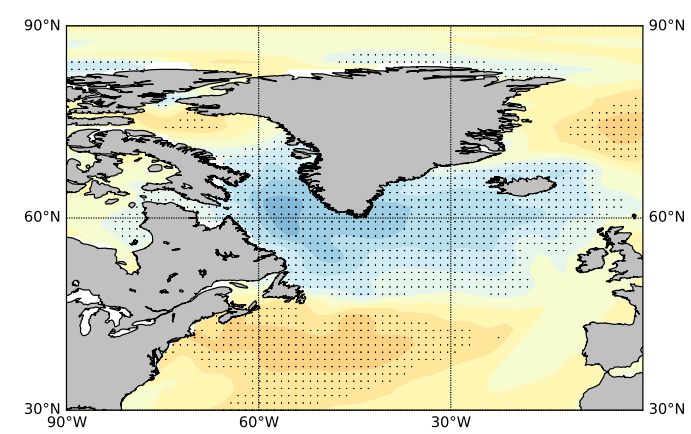

(a)

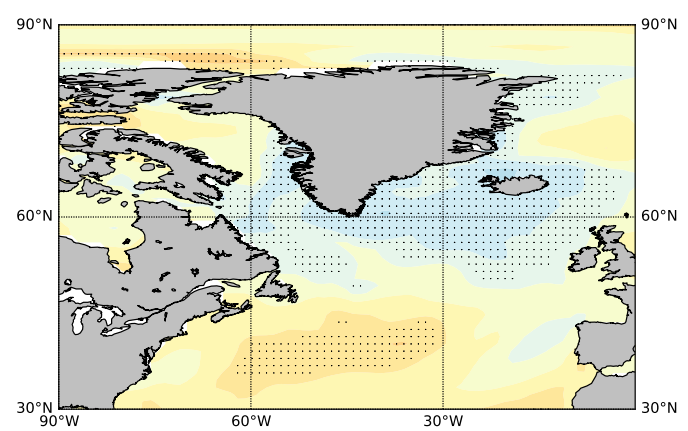

(b)

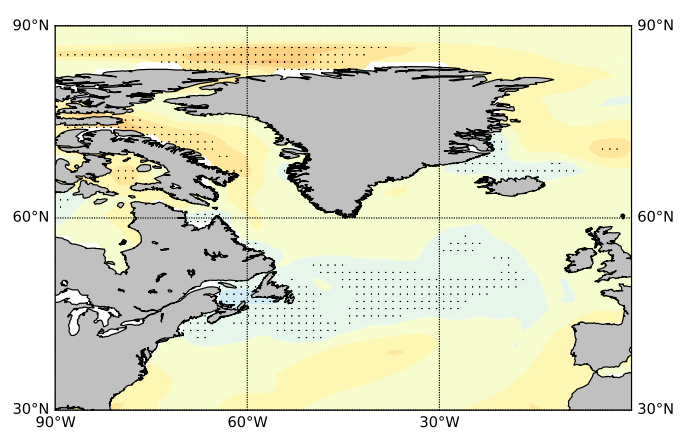

(c)

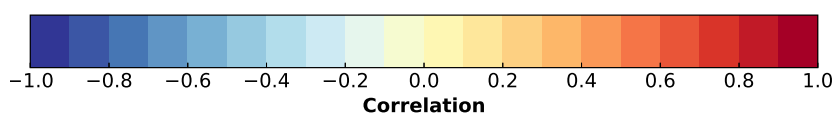

Figure 10: Maps of correlation between the local SST the first July and the Labrador SIE (a) the first, (b) the second and (c) the third February for ECEarth2.3. Correlations were calculated using the ControlRun. Dots represent the significant values at the $95 \%$ level as estimated from a one-sided student-T distribution.

by Blanchard-Wrigglesworth et al. (2011). In September, anomalies of the panArctic SIE are well correlated with anomalies of the SIT in the central Arctic, thus anomalies of the SIE re-emerge from one summer to the next due to the memory of the corresponding SIT anomaly.

In a similar way, peaks of the SIE PPP in the internal Arctic basins during the summers, can be linked to the persistence of the SIT, coherent with the long-lasting persistence of the SIV (Fig. 1 of the supplementary material). In these areas, little connection with the upper ocean should be expected, due to the insulating role played by the sea ice cover during most of the year. 


\section{Conclusions}

In this paper, we analyzed six different control experiments and their correspondent set of 3-year ensemble predictions initialized on 1st July from the control experiment for various start dates. Using this perfect-model protocol, the main objectives of our study were to assess the regional sea ice predictability of the APPOSITE project models, highlight in EC-Earth2.3 some sources and mechanisms for the predictability of the sea ice extent and volume in sub-basins of the Arctic Ocean and the surrounding North Atlantic and Pacific Oceans and investigate how understanding of the regional-scale mechanisms helps to clarify the predictability at the pan-Arctic scale.

The potential predictability was estimated by measuring the growth of the ensemble spread in the idealized predictions, and comparing it to the natural variability derived from the control experiment. We also calculated lagged correlations in the control simulation, as a diagnostic approach to assess the persistence or lagged relationships in the control experiment and thus infer some mechanisms explaining the potential predictability in the idealized predictions. The comparison of the prognostic and diagnostic approaches indicated that lagged correlation is an informative measure of SIE and SIV predictability.

We quantified to what extent the regional Arctic sea ice would be potentially predictable, if we had a perfect knowledge of the initial conditions of the predictions and the simulated processes matched perfectly the observed ones. More focus was put on the mechanisms behind EC-Earth2.3 predictability. For this model the regions could be clustered into three groups according to their predictability: the peripheral seas, the Labrador Sea and the interior Arctic basins.

The main conclusions from this study are:

- Consistent SIE predictability reemergence is found in winter for HadGEM1.2, GFDL-CM3 and E6F, which could be related to the winter negative ice thicknessgrowth rate feedback (Tietsche et al., 2014). The SIV shows greater predictability, attributable to the long-lasting persistence of the SIT in the central Arctic for all models.

- The summer-to-summer reemergence of the PPP of pan-Arctic SIE is consistently related in all models to the persistence of SIT anomalies in the central Arctic.

- The Baffin Bay and the GIN seas SIE exhibit a robust PPP signal among all models, characterized by a winter memory reemergence. For the rest of the regions, we found significant inconsistencies, which we attribute to the differences in the average states of the sea ice.

- For EC-Earth2.3 and in the peripheral seas of the Atlantic Sector, significantly high PPP values over 1 year, including the 1-year reemergence, are driven by the persistence of local oceanic thermal anomalies (SST and OHC).

- In the Labrador Sea (for EC-Earth2.3), which is ice-free in July, the PPP peaks between January and April during the first year are a result of the subpolar gyre persistence. However, the January to April peaks of the second year seem to be related to the advection of ocean temperature anomalies from the Irminger Sea and the Eastern North Atlantic Ocean. 
- In the interior Arctic seas in EC-Earth2.3, winter SIE potential predictability is trivial due to complete ice coverage. In contrast, the SIV has a longer predictability in these seas as a result of the long SIT persistence.

Considering mechanisms which act at regional scales illustrates that sea ice predictability arises from a variety of different sources in the Arctic sectors considered. For instance, we have seen that in EC-Earth2.3 the ocean is a potential source of predictability in the peripheral seas, while the SIT plays a dominant role in the interior seas. These results provide guidance for the design of operational forecasting systems: for lead times beyond a single season, the ocean initial state would play a role in providing skilful forecasts in the marginal ice zone.

Moreover, there are some processes that were not investigated in this paper, but that have been reported in previous studies as sources of sea ice predictability. For instance, the melt-to-freeze reemergence in the Barents and GIN seas has been related to the local SST memory (Bushuk et al., 2015; Schlichtholz, 2011). Other studies have shown that the winter Barents Sea SIA is highly correlated with the heat transport from the Atlantic waters through the Barents Sea Opening (Årthun et al., 2012; Nakanowatari et al., 2014; Onarheim et al., 2015). This inflow of warm water is also driven by the atmospheric variability with 1-2 years lag between the cyclonic anomalies and the ice response (Sorteberg and Kvingedal, 2006).

Previous studies have shown that state-of-the-art coupled models exhibit similar sea ice predictability properties, like the melt-to-freeze or summer-to-summer correlation reemergence (Day et al., 2014). However, Tietsche et al. (2014) suggested some model dependency: for instance, they suggested that the representation of advective processes could be more model-dependent than the thermodynamic ones. The extent to which some of the mechanisms are documented in the present paper for EC-Earth2.3 should be discussed, especially by applying similar diagnostics to other models. One important aspect is the possible role of model biases in shaping some mechanisms, especially on the Pacific side where there is virtually no potential predictability in EC-Earth2.3 (Guemas et al., 2014).

Prior works addressed the dependence of predictability on the initialization month (Blanchard-Wrigglesworth et al., 2011; Day et al., 2014) and on the mean climate. For instance, Goosse et al. (2009) suggested an initial decrease of the predictability of summer Arctic SIE due to increased variability during the twenty-first century. Our present study may provide some insight into possible future regimes of the pan-Arctic sea ice cover in the future. Summer-to-summer reemergence in the pan-Arctic SIE PPP is due to the presence of perennial sea ice surviving the melt season. In a warmer climate, predictability of the Arctic sea ice cover may be closer to that of the peripheral seas, with predictability dominated by more ocean-related mechanisms.

Acknowledgements We thank Jonathan Day and Steffen Tietsche for providing the data for the ocean heat transport into the Arctic; Nicolau Manubens, Javier Vegas-Regidor and PierreAntoine Bretonnière for the technical support; Pablo Ortega for useful comments on the presubmission draft. We thank Javier García-Serrano for useful discussions regarding this study and Alasdair Hunter for the revision of the English. We give thanks to two anonymous reviewers for their insightful comments that improved the manuscript. The R-package s2dverification was used for processing the data and calculating different scores (Manubens et al., 2018). We acknowledge the Ariane tool and its creators (http://stockage.univ-brest.fr/ grima/Ariane/). We also thank the projects APPLICATE (H2020 GA 727862), INTAROS (H2020 GA 727890), the programme Copernicus and the fellowships Ramón y Cajal (MINECO) and Formación de 

work.

\section{References}

Årthun, M., Eldevik, T., Smedsrud, L. H., Skagseth, Ø., and Ingvaldsen, R. (2012). Quantifying the influence of atlantic heat on barents sea ice variability and retreat. Journal of Climate, 25(13):4736-4743.

Bhatt, U. S., Walker, D. A., Walsh, J. E., Carmack, E. C., Frey, K. E., Meier, W. N., Moore, S. E., Parmentier, F.-J. W., Post, E., Romanovsky, V. E., et al. (2014). Implications of arctic sea ice decline for the earth system. Annual Review of Environment and Resources, 39:57-89.

Bitz, C., Holland, M., Hunke, E., and Moritz, R. (2005). Maintenance of the sea-ice edge. Journal of climate, 18(15):2903-2921.

Blanchard-Wrigglesworth, E., Armour, K. C., Bitz, C. M., and DeWeaver, E. (2011). Persistence and inherent predictability of arctic sea ice in a gcm ensemble and observations. Journal of Climate, 24(1):231-250.

Blanchard-Wrigglesworth, E., Barthélemy, A., Chevallier, M., Cullather, R., Fučkar, N., Massonnet, F., Posey, P., Wang, W., Zhang, J., Ardilouze, C., et al. (2016). Multi-model seasonal forecast of arctic sea-ice: forecast uncertainty at pan-arctic and regional scales. Climate Dynamics, pages 1-12.

Blanke, B., Arhan, M., Madec, G., and Roche, S. (1999). Warm water paths in the equatorial atlantic as diagnosed with a general circulation model. Journal of Physical Oceanography, 29(11):2753-2768.

Blanke, B. and Raynaud, S. (1997). Kinematics of the pacific equatorial undercurrent: An eulerian and lagrangian approach from gcm results. Journal of Physical Oceanography, 27(6):1038-1053.

Boer, G. J. (2004). Long time-scale potential predictability in an ensemble of coupled climate models. Climate dynamics, 23(1):29-44.

Bushuk, M., Msadek, R., Winton, M., Vecchi, G., Yang, X., Rosati, A., Gudgel, R. (2018). Regional Arctic sea-ice prediction: potential versus operational seasonal forecast skill. Climate Dynamics, 1-23.

Bushuk, M., Giannakis, D., and Majda, A. J. (2015). Arctic sea ice reemergence: The role of large-scale oceanic and atmospheric variability. Journal of Climate, 28(14):5477-5509.

Cheng, W., Blanchard-Wrigglesworth, E., Bitz, C. M., Ladd, C., and Stabeno, P. J. (2016). Diagnostic sea ice predictability in the pan-arctic and us arctic regional seas. Geophysical Research Letters, 43(22).

Collins, M. (2002). Climate predictability on interannual to decadal time scales: the initial value problem. Climate Dynamics, 19(8):671-692.

Day, J., Tietsche, S., Collins, M., Goessling, H., Guemas, V., Guillory, A., Hurlin, W., Ishii, M., Keeley, S., Matei, D., et al. (2016). The arctic predictability and prediction on seasonal-to-interannual timescales (apposite) data set. Geoscientific Model Development, 8(10).

Day, J., Tietsche, S., and Hawkins, E. (2014). Pan-arctic and regional sea ice predictability: Initialization month dependence. Journal of Climate, 27(12):43714390 . 
Deser, C., Tomas, R., Alexander, M., and Lawrence, D. (2010). The seasonal atmospheric response to projected arctic sea ice loss in the late twenty-first century. Journal of Climate, 23(2):333-351.

Donner, L. J., Wyman, B. L., Hemler, R. S., Horowitz, L. W., Ming, Y., Zhao, M. Golaz, J.-C., Ginoux, P., Lin, S.-J., Schwarzkopf, M. D., et al. (2011). The dynamical core, physical parameterizations, and basic simulation characteristics of the atmospheric component am3 of the gfdl global coupled model $\mathrm{cm} 3$. Journal of Climate, 24(13):3484-3519.

Francis, J. A. and Hunter, E. (2007). Drivers of declining sea ice in the arctic winter: A tale of two seas. Geophysical Research Letters, 34(17).

Francis, J. A. and Vavrus, S. J. (2012). Evidence linking arctic amplification to extreme weather in mid-latitudes. Geophysical Research Letters, 39(6).

Germe, A., Chevallier, M., y Mélia, D. S., Sanchez-Gomez, E., and Cassou, C. (2014). Interannual predictability of arctic sea ice in a global climate model: regional contrasts and temporal evolution. Climate Dynamics, 43(9-10):25192538.

Goessling, H. F., Tietsche, S., Day, J. J., Hawkins, E., and Jung, T. (2016). Predictability of the arctic sea ice edge. Geophysical Research Letters, 43(4):16421650 .

Goosse, H., Arzel, O., Bitz, C. M., de Montety, A., and Vancoppenolle, M. (2009). Increased variability of the arctic summer ice extent in a warmer climate. Geophysical Research Letters, 36(23).

Griffies, S. M., Winton, M., Donner, L. J., Horowitz, L. W., Downes, S. M., Farneti, R., Gnanadesikan, A., Hurlin, W. J., Lee, H.-C., Liang, Z., et al. (2011). The gfdl cm3 coupled climate model: characteristics of the ocean and sea ice simulations. Journal of Climate, 24(13):3520-3544.

Guemas, V., Doblas-Reyes, F. J., Mogensen, K., Keeley, S., and Tang, Y. (2014). Ensemble of sea ice initial conditions for interannual climate predictions. Climate dynamics, 43(9-10):2813-2829.

Hassol, S. J. (2004). Impacts of a warming Arctic-Arctic climate impact assessment. Cambridge University Press.

Hazeleger, W., Wang, X., Severijns, C., Ştefănescu, S., Bintanja, R., Sterl, A., Wyser, K., Semmler, T., Yang, S., Van den Hurk, B., et al. (2012). Ec-earth v2. 2: description and validation of a new seamless earth system prediction model. Climate Dynamics, 39(11):2611-2629.

Holland, M. M., Bailey, D. A., and Vavrus, S. (2011). Inherent sea ice predictability in the rapidly changing arctic environment of the community climate system model, version 3. Climate dynamics, 36(7-8):1239-1253.

Johns, T. C., Durman, C. F., Banks, H. T., Roberts, M. J., McLaren, A. J., Ridley, J. K., Senior, C. A., Williams, K., Jones, A., Rickard, G., et al. (2006). The new hadley centre climate model (hadgem1): Evaluation of coupled simulations. Journal of Climate, 19(7):1327-1353.

Jungclaus, J., Fischer, N., Haak, H., Lohmann, K., Marotzke, J., Matei, D., Mikolajewicz, U., Notz, D., and Storch, J. (2013). Characteristics of the ocean simulations in the max planck institute ocean model (mpiom) the ocean component of the mpi-earth system model. Journal of Advances in Modeling Earth Systems, $5(2): 422-446$.

Koenigk, T. and Mikolajewicz, U. (2009). Seasonal to interannual climate predictability in mid and high northern latitudes in a global coupled model. Climate 
dynamics, 32(6):783.

4 Liu, J., Curry, J. A., Wang, H., Song, M., and Horton, R. M. (2012). Impact of declining arctic sea ice on winter snowfall. Proceedings of the National Academy of Sciences, 109(11):4074-4079.

Manubens, N., Caron, L.-P., Hunter, A., Bellprat, O., Exarchou, E., Fučkar, N. S., Garcia-Serrano, J., Massonnet, F., Ménégoz, M., Sicardi, V., et al. (2018). An r package for climate forecast verification. Environmental Modelling ES Software, 103:29-42.

Nakanowatari, T., Sato, K., and Inoue, J. (2014). Predictability of the barents sea ice in early winter: Remote effects of oceanic and atmospheric thermal conditions from the north atlantic. Journal of Climate, 27(23):8884-8901.

Notz, D., Haumann, F. A., Haak, H., Jungclaus, J. H., and Marotzke, J. (2013). Arctic sea-ice evolution as modeled by max planck institute for meteorology's earth system model. Journal of Advances in Modeling Earth Systems, 5(2):173194.

Onarheim, I. H., Eldevik, T., Årthun, M., Ingvaldsen, R. B., and Smedsrud, L. H. (2015). Skillful prediction of barents sea ice cover. Geophysical Research Letters, 42(13):5364-5371.

Pohlmann, H., Botzet, M., Latif, M., Roesch, A., Wild, M., and Tschuck, P. (2004). Estimating the decadal predictability of a coupled aogcm. Journal of Climate, 17(22):4463-4472.

Schlichtholz, P. (2011). Influence of oceanic heat variability on sea ice anomalies in the nordic seas. Geophysical Research Letters, 38(5).

Serreze, M. C. and Barry, R. G. (2011). Processes and impacts of arctic amplification: A research synthesis. Global and Planetary Change, 77(1):85-96.

Shaffrey, L. C., Stevens, I., Norton, W., Roberts, M., Vidale, P. L., Harle, J., Jrrar, A., Stevens, D., Woodage, M. J., Demory, M.-E., et al. (2009). Uk higem: The new uk high-resolution global environment model - model description and basic evaluation. Journal of Climate, 22(8):1861-1896.

Sidorenko, D., Rackow, T., Jung, T., Semmler, T., Barbi, D., Danilov, S., Dethloff, K., Dorn, W., Fieg, K., Gößling, H. F., et al. (2015). Towards multi-resolution global climate modeling with echam6-fesom. part i: model formulation and mean climate. Climate Dynamics, 44(3-4):757-780.

Sorteberg, A. and Kvingedal, B. (2006). Atmospheric forcing on the barents sea winter ice extent. Journal of Climate, 19(19):4772-4784.

Stammerjohn, S., Massom, R., Rind, D. and Martinson, D. (2012). Regions of rapid sea ice change: An inter-hemispheric seasonal comparison. Geophysical Research Letters, 39(20).

Tietsche, S., Day, J., Guemas, V., Hurlin, W., Keeley, S., Matei, D., Msadek, R., Collins, M., and Hawkins, E. (2014). Seasonal to interannual arctic sea ice predictability in current global climate models. Geophysical Research Letters, 41(3):1035-1043.

Tietsche, S., Hawkins, E., and Day, J. J. (2016). Atmospheric and oceanic contributions to irreducible forecast uncertainty of arctic surface climate. Journal of Climate, 29(1):331-346.

Vihma, T. (2014). Effects of arctic sea ice decline on weather and climate: a review. Surveys in Geophysics, 35(5):1175-1214.

Watanabe, M., Suzuki, T., O’ishi, R., Komuro, Y., Watanabe, S., Emori, S., Takemura, T., Chikira, M., Ogura, T., Sekiguchi, M., et al. (2010). Improved climate 
simulation by miroc5: Mean states, variability, and climate sensitivity. Journal of Climate, 23(23):6312-6335.

Wouters, B., Hazeleger, W., Drijfhout, S., Oldenborgh, G., and Guemas, V. (2013). Multiyear predictability of the north atlantic subpolar gyre. Geophysical Research Letters, 40(12):3080-3084.

Yang, S. and Christensen, J. H. (2012). Arctic sea ice reduction and european cold winters in cmip5 climate change experiments. Geophysical Research Letters, $39(20)$. 